\title{
Vitamin D deficiency in non-autoimmune hypothyroidism: a case-control study
}

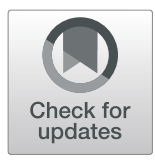

Salma Ahi ${ }^{* *}$, Mohammad Reza Dehdar ${ }^{2}$ and Naser Hatami ${ }^{2}$

\begin{abstract}
Background: Although in many studies, the relationship between autoimmune hypothyroidism (Hashimoto) and Vitamin $D$ deficiency was shown, no research has been performed on the role of vitamin $D$ in non-autoimmune hypothyroidism.

Methods: This was a case-control study in Endocrinology clinic of Jahrom (south of Iran). The patients with Hashimoto $(n=633)$ and non-Hashimoto hypothyroidism $(n=305)$, along with a control group $(n=200)$ were evaluated. 25(OH) D level, T3 and T4 levels were studied and Anti TPO and Anti TG tests were performed. The results of vitamin D level were analyzed and interpreted using SPSS in terms of the cause of hypothyroidism (immune and non-immune).

Results: The results of the study showed a significantly lower level of vitamin $D$ in both immune and non-immune Hashimoto's thyroiditis (HT) in comparison to healthy controls $(P<0.05)$. We observed a significant inverse correlation between the vitamin D and TGAb level $(p=0.001, r=-0.261)$ and a direct correlation of vitamin $D$ with TSH level $(p=0.008, r=0.108)$ in Hashimoto thyroiditis patients.

Conclusion: Finally, the results indicated that non-autoimmune hypothyroidism, as well as HT, is associated with vitamin D deficiency. The role of vitamin D deficiency in Hashimoto thyroiditis was thought to be in the association of higher autoantibody (TGAb) level; while, there should be further studies determining vitamin D deficiency's role in non-immune hypothyroidism.
\end{abstract}

\section{Background}

Vitamin D receptors exist in many body organs. Through these receptors, vitamin D has various functions, including the regulation of ion homeostasis, cell growth, cell differentiation, and cellular immunity [1]. Vitamin D plays an important role in preventing the occurrence of many inflammatory diseases, infections, and autoimmune diseases [2]. In numerous studies, the relationship between vitamin $\mathrm{D}$ deficiency and a variety of diseases, including musculoskeletal [3], cardiovascular [4], kidney disease [5], diabetes [6] and infections [7] had been shown. The thyroid gland

\footnotetext{
* Correspondence: salmaahi.61@gmail.com

${ }^{1}$ Research Center for Noncommunicable Diseases, Jahrom University of Medical Sciences, Jahrom, Iran

Full list of author information is available at the end of the article
}

is also one of the organs that have a receptor for vitamin D. The vitamin $\mathrm{D}$ receptor in the thyroid is a member of a large group of receptors called nuclear receptors, which also belong to the thyroid hormones receptor [8]. Some studies indicated that vitamin D deficiency is associated with various autoimmune diseases [9]. Today, Hashimoto is one of the most common acquired hypothyroidism and autoimmune disease in children and adults [10]. The onset of autoimmune-thyroid disease with vitamin D deficiency is very common [11]. Plenty of evidence has shown the role of vitamin $\mathrm{D}$ in the regulation of proinflammatory cytokines, regulatory $\mathrm{T}$ cell, and immune response [12]. It seems that vitamin D deficiency leads to an increase in the risk of autoimmune diseases. Vitamin D also can reduce the pathogenesis of DCs cells, macrophage, CD4 + T, CD8 + T, and B cells [9]. Besides, it has 
been shown as a selective immune inhibitor that plays an important role in suppressing and preventing the development of autoimmune diseases such as encephalopathy, rheumatoid arthritis, systemic lupus erythematosus, diabetes type 1, and intestinal inflammatory diseases [13-15]. Recent studies have shown the role of vitamin D deficiency in autoimmune thyroids, such as Hashimoto thyroiditis $[16,17]$. To the best of our knowledge, there is contradictory research about the relationship between thyroid diseases, especially hypothyroidism and vitamin $\mathrm{D}$ deficiency; therefore, in the present study, we aimed to evaluate the vitamin $\mathrm{D}$ level in hypothyroidism patients. Besides, there was no study comparing the vitamin D level in immune and non-immune hypothyroidism, and the relationship between the anti-TPO level and vitamin D, as well as the disease treatment status and vitamin D; hence, in the present study we evaluated the mentioned issues.

\section{Method}

\section{Study size and participants}

In the present cross-sectional case control study, all hypothyroidism patients were selected among referents to the endocrinology clinic of Jahrom city in 2018. In the study, the treatment group included patients with prediagnosed hypothyroidism under Levothyroxine therapy or newly diagnosed patients. Written informed consent was acquired from all study subjects. Control group consisted of healthy people, who were similar to other groups in terms of confounding variables. Exclusion criteria were to have collagen vascular and Celiac disease and type-1 diabetes mellitus. Finally, 633 Immune Hypothyroid and 305 non-Immune Hypothyroid and 200 healthy subjects were enrolled (Fig. 1). The exclusion criteria for this study were type 1 diabetes, lupus, collagen vascular disease, rheumatoid arthritis, celiac disease, and also patients who underwent vitamin $\mathrm{D}$ supplementation and vitamin $\mathrm{D}$ interacting medications (such as antacids, corticosteroids, orlistat, diabetes medications, antihypertensive drugs, cholestyramine, antiepileptics, calcium supplements). While the participants enrolment were done based on their previous thyroid function workups during referral to thyroid clinic, to investigate the disease and vitamin D interactions, new blood samples were taken to evaluate both vitamin D levels and thyroid function tests in same time at last month of summer with adequate sun exposure. Because, the circulating vitamin D levels ranges from season to season, in our study all blood samples were taken at the same period of august 2018; so, the confounding effect of seasonal variations of vitamin $\mathrm{D}$ was eliminated.

\section{Outcome definition}

Normal thyroid function was considered as $0.3 \mathrm{mIU} / \mathrm{L} \leq$ $\mathrm{TSH} \leq 3.6 \mathrm{mIU} / \mathrm{L}$. The diagnosis of overt and subclinical hypothyroidism respectively was done based on TSH levels higher than 10 and $3.6 \mathrm{mIU} / \mathrm{L}<\mathrm{TSH} \leq 10 \mathrm{mIU} / \mathrm{L}$ [18]. Normal T4 levels were considered between 4.5 and $12.0 \mu \mathrm{g} / \mathrm{dL}$ for normal participants. T4 value lower than 4.5 was one of the additional criteria' for hypothyroidism

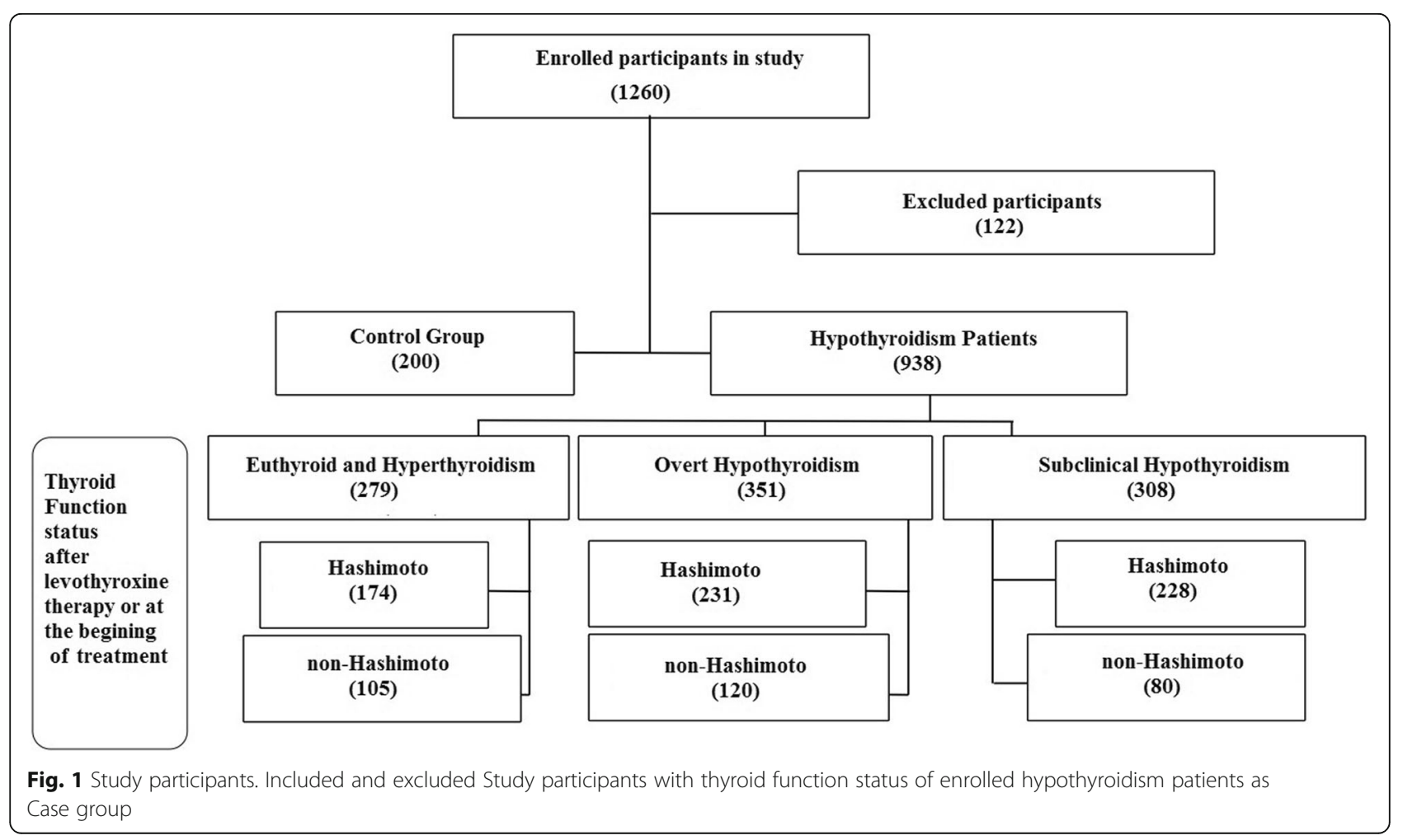


patients [18]. The values higher than 40 and $100 \mathrm{IU} / \mathrm{mL}$ were considered positive for TPOAb and TGAb, respectively. Diagnosis criteria for Hashimoto thyroiditis included decreased T4 value along with an elevated TSH (Overt and subclinical hypothyroidism patients) and the presence of high serum TPOAb or TGAb concentrations. The patients having overt or subclinical hypothyroidism without positive TPOAb or TGAb were considered as having non-autoimmune hypothyroidism disease. Vitamin D levels lower than $8 \mathrm{ng} / \mathrm{mL}$ were considered as severe vitamin D deficiency, $9-15 \mathrm{ng} / \mathrm{mL}$ concentrations as mild vitamin $\mathrm{D}$ deficiency, higher than 16 to $20 \mathrm{ng} / \mathrm{mL}$ concentrations as vitamin D insufficiency and higher than $20 \mathrm{ng} / \mathrm{mL}$ concentrations as normal vitamin D level [19].

\section{Laboratory measurements}

Blood samples were taken from all participants after at least $8 \mathrm{~h}$ of fasting. T3, Free T4, TSH were measured by Cobas ECLIAs (Roche Diagnostics GmbH, Mannheim, Germany). Thyroid peroxidase antibody (TPOAb) were determined by chemiluminiscenta IMMULITE 2000 XPi (Siemens, Eschborn, Germany). Thyroid globulin antibody (TGAb) levels were analyzed by Enzyme-Linked Immunosorbent Assay (ELISA kit, Diesel). Vitamin D levels were measured by LIAISON vitamin D chemiluminescence immunoassay (DiaSorin, Saluggia, Italy).

\section{Statistical methods}

In order to compare the quantitative continuous variables, ANOVA for parametric data and Man-u withney and Kruskal Wallis for non-parametric data were used. Chi-square test was used to compare discrete data among different groups. A $p$-value of less than 0.05 was considered statistically significant. SPSS v.19 was used for statistical analysis.

\section{Result}

Totally 1138 individuals were studied. Demographic information and biochemical parameters of participants are presented in Table 1 . Total vitamin D level of participants was 15.4(8.41-25.87). Male participants had a higher level of vitamin $\mathrm{D}(p=0.001)$, based on the Mann-Whitney U test results. While, There wasn't any significant difference in distribution of male and female participants in study groups $(P=0.751)$. There wasn't any significant difference in the age of participants of Immune Hypothyroid, Non-Immune Hypothyroid and Control groups $(p=0.630)$.

Kruskal Wallis test revealed that there was a significant difference in Vitamin D level of study groups. As shown in Fig. 2. Control subjects had significantly higher vitamin D level than both Hashimoto thyroiditis $(p=$ 0.001 ) and Non-autoimmune thyroid disease patients $(p=0.001)$, but there wasn't any significant difference between vitamin $\mathrm{D}$ level of Hashimoto thyroiditis and Non-Immune Hypothyroid patients $(p=0.923)$, as shown in supplementary table 1 .

The comparison of study variables between Hashimoto thyroiditis and non-autoimmune hypothyroid groups are provided in Supplementary Table 1. This comparisons didn't revealed significant difference in vitamin D levels between Hashimoto thyroiditis and non-autoimmune patients $(P=0.923)$. Also the correlations between vitamin $\mathrm{D}$ and study variables were evaluated and reported in supplementary file 1 .

As shown in Table 2, to investigate the relationship of the thyroid autoimmunity in Hashimoto thyroiditis patients and vitamin $\mathrm{D}$, a chi-square test investigated the distribution of the vitamin $\mathrm{D}$ deficiency occurrence in $\mathrm{TPOAb}+$ and $\mathrm{TGAb}+$ patients. The results revealed a significantly higher rate of $\mathrm{TPOAb}+$ in vitamin $\mathrm{D}$ deficient patients $(p=0.030)$, however, there weren't any differences in the occurrence of TGAb+ in vitamin $\mathrm{D}$ deficient and sufficient patients $(p=0.14)$.

Table 1 Basal characteristic of patients

\begin{tabular}{|c|c|c|c|c|}
\hline Characteristic & Immune Hypothyroid & Non-Immune Hypothyroid & control & $\boldsymbol{P}$ Value* $^{*}$ \\
\hline Number & 633 & 305 & 200 & - \\
\hline Age years $($ mean \pm s.d.) & $37.48 \pm 13.18$ & $36.65 \pm 14.56$ & $37.69 \pm 15.26$ & 0.630 \\
\hline Sex (male), n (\%) & $146(23.1)$ & $66(21.6)$ & $49(24.5)$ & 0.751 \\
\hline Vitamin D level, ng/ml (IQR) & $13.22(8.1-24.27)$ & $16(8.43-28.85)$ & 20.4(11.2-29.6) & 0.001 \\
\hline TSH, mlu/l (IQR) & $6.29(3.13-17.75)$ & $5.92(2.54-1.81)$ & $2.2(1.59-2.88)$ & 0.001 \\
\hline $\mathrm{T} 3, \mathrm{mg} / \mathrm{ml}(\mathrm{IQR})$ & $1.67(1.26-2.38)$ & $1.68(1.22-2.15)$ & 1.32(0.74-1.8) & 0.001 \\
\hline $\mathrm{T} 4, \mathrm{mg} / \mathrm{ml}$ (IQR) & $9.1(7.06-63.62)$ & $11.1(7.42-80.05)$ & $7.05(0.63-808)$ & 0.001 \\
\hline TPOAb, IU/mL (IQR) & 14.4(4.69-134.6) & $3.59(1.13-16.67)$ & 19.4(13.6-33.55) & 0.001 \\
\hline TGAb, IU/mL (IQR) & $320.7(112.2-733)$ & 10(4.33-15.63) & 16.9(9.16-185.95) & 0.001 \\
\hline
\end{tabular}

* Kruskal-Wallis one-way analysis of variance. $P$ value less than 0.05 is considered significant. Normally distributed variables are shown as mean \pm s.d. nonparametric variables are shown as median (IQR). IQR Interquartile range. $n$ Number, TSH Thyroid stimulating hormone. TPOAb Thyroid Autoantibodies, TGAb thyroglobulin antibodies 


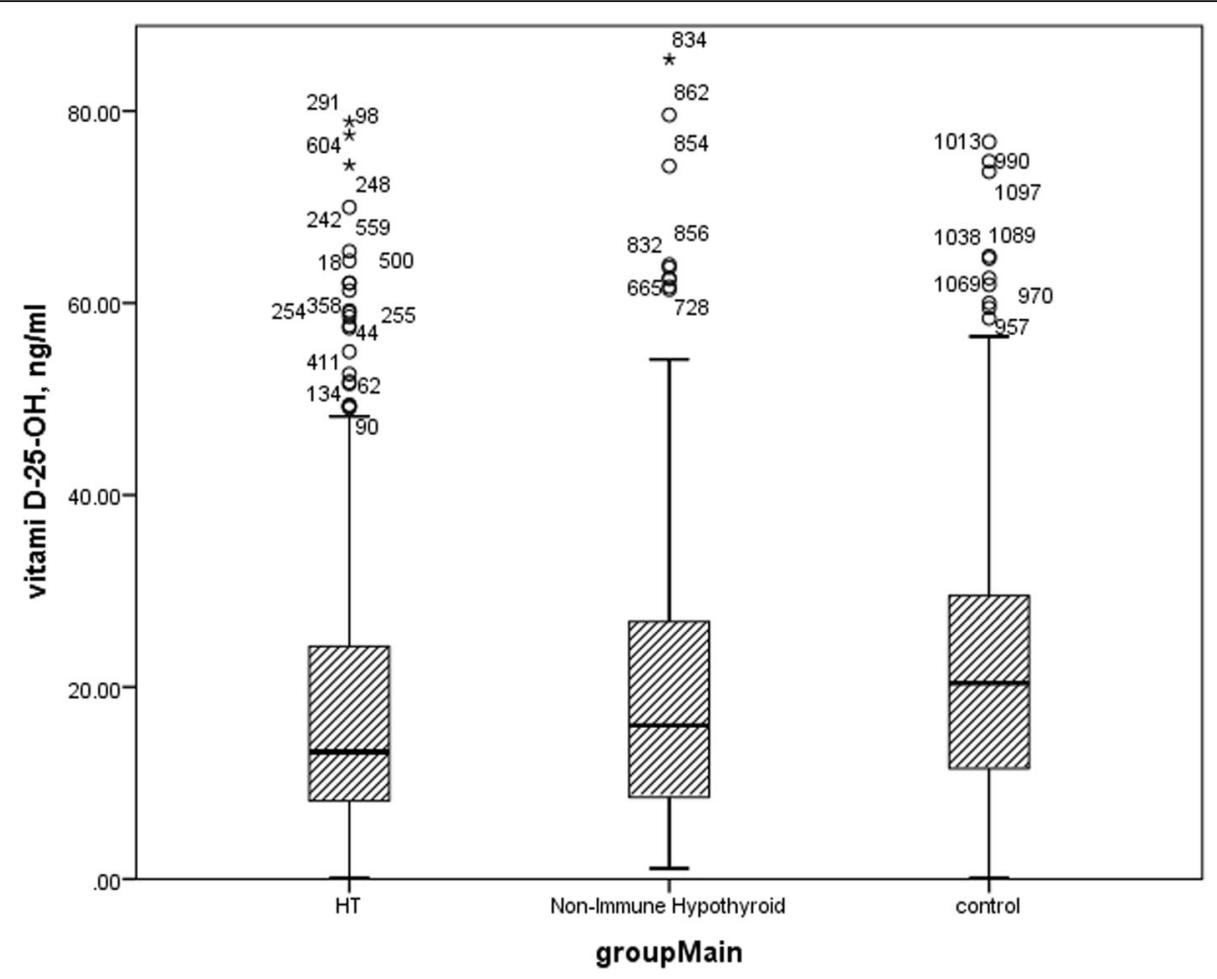

Fig. 2 Vitamin D level of study group. Box plot of vitamin D levels in study groups. HT: Hashimoto thyroiditis

The spearman test was used to investigate correlation of nonparametric variables including vitamin $\mathrm{D}$ and autoantibodies. The results revealed that in Hashimoto thyroiditis patients there was a significant inverse correlation between the vitamin $\mathrm{D}$ and TGAb level $(p=0.001, \mathrm{r}=-$ 0.261 ) and a direct correlation of vitamin D with TSH level $(p=0.008, \mathrm{r}=0.108)$. However, there wasn't any significant correlation between vitamin $\mathrm{D}$ and other paraclinical findings). Also, these correlations were not statistically significant in Non-Immune Hypothyroid and Control.

\section{Discussion}

Hypothyroidism is a hypothalamus-pituitary-thyroid imbalance in the central axis and insufficient secretion of the regulatory hormones for thyroid gland [20]. Hypothyroidism may has various reasons that the most common causes are Hashimoto or autoimmune thyroid problems and iodine disorders [21]. Previous studies have been explained the role of vitamin $\mathrm{D}$ in preventing autoimmune thyroid disease.

Table 2 Thyroid autoimmunity in Hashimoto thyroiditis patients

\begin{tabular}{llll}
\hline & $\begin{array}{l}\text { Vitamin D } \\
\text { Sufficient } \\
(>20 \mathrm{ng} / \mathrm{ml})\end{array}$ & $\begin{array}{l}\text { Vitamin D } \\
\text { Deficient } \\
(<20 \mathrm{ng} / \mathrm{ml})\end{array}$ & ${ }^{*} \boldsymbol{p}$ value \\
\hline TPOAb+, $\mathbf{n}$ & 195 & 422 & 0.030 \\
TGAb+, $\mathbf{n}$ & 9 & 34 & 0.140 \\
\hline
\end{tabular}

* Chi square test. $P$ value less than 0.05 is considered significant. $n$ number, $T P O A b$ Thyroid Autoantibodies, TGAb Thyroglobulin antibodies
Vitamin D prevents aberrant immune responses by modulating the immune cells [22]. However, Vitamin D may affect thyroid function in other ways than modulating the immune system and preventing autoimmune diseases. A limited number of studies were performed in the field of evaluating vitamin $\mathrm{D}$ effect in non-immune hypothyroidism disease.

The results of the present research indicated that hypothyroidism patients with or without an immune base, deal with vitamin $D$ deficiency $(<20 \mathrm{ng} / \mathrm{mL})$ more than healthy people. In the study of Evliyaoğlu et al. [23], the patients with $<20 \mathrm{ng} / \mathrm{mL}$ vitamin D level was considered as vitamin $\mathrm{D}$ deficient and they showed that the prevalence of vitamin D deficiency is more common in people with Hashimoto than normal people. The results of their study were in agreement with those of the present study and other similar researches $[16,17,24]$. In the present study, a remarkable finding was the association between non-autoimmune hypothyroidism and vitamin D deficiency. It means that the vitamin D deficiency level in a patient with non-Hashimoto hypothyroidism was higher than the control group. The relationship between vitamin D deficiency and Hashimoto thyroiditis is well documented. The prevalence of positive TPOAb among people with $<20 \mathrm{ng} / \mathrm{mL}$ vitamin $\mathrm{D}$ level was more than people with sufficient vitamin D.

Krysiak et al. [25] indicated that daily uptake of 2000 IU and vitamin D can improve the treatment process in women with HT. Of course, the relationship between 
Hashimoto and vitamin D may also be affected by the patient's condition. Some scholars believe that there are some differences in the past time since the onset of the disease. Effraimidis et al. [26] stated that there is no relationship between vitamin D level and primary stage of autoimmune thyroid disease. However, our subjects had crossed the initial stage of the disease. Age and sex differences may also be effective. In the present research, the male had a higher level of vitamin D than women.

Colbay et al. showed the negative correlation between TSH and vitamin D level [27]. Zhang et al. [28] indicated that the higher level of vitamin $\mathrm{D}$ leads to a reduction of circulated TSH, which are not in agreement with the results of our study. But in non-immune hypothyroidism, vitamin D didn't correlate with TSH. This shows the diverse probable role of vitamin D deficiency in the pathogenesis of Hashimoto thyroiditis or non-immune hypothyroidism.

The subjects of the present study were under Levothyroxine therapy, as an effective factor on TSH level, interpreting the results based TSH and finding the relationship between vitamin $\mathrm{D}$ and thyroid function was not reliable. Barsony et al. [29] demonstrated that the treatment of hypothyroidism with Levothyroxine led to an increase in vitamin D level. While Cayir et al. showed that long-term consumption of levothyroxine may disrupt the concentration of vitamin D [30]. Therefore, there is a complicated relationship between them. Besides, similar clinical and laboratory studies did not address this issue, and they only showed the relationship between Hashimoto thyroiditis and vitamin D. Fournier et al. induced autoimmune thyroid disease on laboratory mice model and showed the positive effect of vitamin D on suppressing of immune system and prevention of thyroid autoimmune damage [31]. However, the present study showed that vitamin D deficiency not only affects the immune system but also have a relationship with the function of the thyroid gland directly.

One of the strong points of the present study is the evaluation of vitamin D level in hypothyroidism patients who their disease wasn't autoimmune. In the present study, TGAb and TPOAb antibodies were evaluated in thyroid patients, but other factors were not evaluated. The different stage of disease in participants was the limitation of the study. For future researches, we suggest matching factors such as the stage of the disease and the dosage of daily received drugs.

\section{Conclusion}

Finally it can be concluded that vitamin D deficiency may have direct associations with thyroid gland function and indirectly may affect thyroid by modulating immune system. However, further studies are needed to identify the exact molecular mechanism of this hypothesis in nonimmune hypothyroidism. Also, screening for vitamin D deficiency may be helpful in all hypothyroid patients.

\section{Supplementary information}

Supplementary information accompanies this paper at https://doi.org/10. 1186/s12902-020-0522-9.

Additional file 1: Table S1. Comparison of study variables in Immune vs. Non-Immune Hypothyroid.

\section{Acknowledgments}

We would like to thank the Clinical Research Development Unit of

Peymanieh Educational and research and therapeutic Center of Jahrom

University of medical sciences for providing facilities for this work.

\section{Authors' contributions}

The manuscript has been read and approved by all authors. All persons listed as authors have contributed to preparing the manuscript. SA designed the study and sample collecting was done by SA and MD. SA and $\mathrm{NH}$ undertook data analysis and writing the manuscript and reversions.

\section{Funding}

We didn't received any grant from funding agencies.

\section{Availability of data and materials}

There isn't any additional data but the data sets are available on the internal medicine department of Jahrom University of medical sciences and would be shared with anyone providing reason for using dataset by contacting the corresponding author

Ethics approval and consent to participate

The study was approved by the ethics committee of Jahrom University of medical sciences and written informed consent was acquired from all study subjects

Consent for publication

There was no personal identifying information in this article.

\section{Competing interests}

The authors declare that they have no competing interests.

\section{Author details}

${ }^{1}$ Research Center for Noncommunicable Diseases, Jahrom University of Medical Sciences, Jahrom, Iran. ${ }^{2}$ Student Research Committee, Jahrom University of Medical Sciences, Jahrom, Iran.

Received: 29 August 2019 Accepted: 5 March 2020

Published online: 20 March 2020

References

1. Wang Y, Zhu J, DeLuca HF. Where is the vitamin D receptor? Arch Biochem Biophys. 2012;523(1):123-33.

2. Kulie T, Groff A, Redmer J, Hounshell J, Schrager S. Vitamin D: an evidencebased review. J Am Board Family Med. 2009;22(6):698-706.

3. Christodoulou S, Goula T, Ververidis A, Drosos G. Vitamin D, and bone disease. Biomed Res Int. 2013;2013:396541.

4. Wang TJ, Pencina MJ, Booth SL, Jacques PF, Ingelsson E, Lanier K, Benjamin EJ, D'Agostino RB, Wolf M, Vasan RS. Vitamin D deficiency and risk of cardiovascular disease. Circulation. 2008:117(4):503-11.

5. Al-Badr W, Martin KJ. Vitamin D and kidney disease. Clin J Am Soc Nephrol. 2008;3(5):1555-60.

6. Berridge MJ. Vitamin D deficiency and diabetes. Biochem J. 2017;474(8): 1321-32.

7. Yamshchikov A, Desai N, Blumberg H, Ziegler T, Tangpricha V. Vitamin D for treatment and prevention of infectious diseases: a systematic review of randomized controlled trials. Endocr Pract. 2009:15(5):438-49.

8. Haussler MR, Haussler CA, Jurutka PW, Thompson PD, Hsieh JC, Remus LS, Selznick SH, Whitfield GK. The vitamin D hormone and its nuclear receptor: molecular actions and disease states. J Endocrinol. 1997;154(3 Suppl):S5773.

9. Dankers W, Colin EM, van Hamburg JP, Lubberts E. Vitamin D in autoimmunity: molecular mechanisms and therapeutic potential. Front Immunol. 2017;7:697. 
10. Hidaka Y. Chronic thyroiditis (Hashimoto's disease). Nippon Rinsho. 2005; 63(Suppl 10):111-5 Review.

11. Clinckspoor I, Gérard AC, Van Sande J, Many MC, Verlinden L, Bouillon R, Carmeliet G, Mathieu C, Verstuyf A, Decallonne B. The vitamin D receptor in thyroid development and function. Eur Thyroid J. 2012;1(3):168-75.

12. Thacher TD, Clarke BL. Vitamin D insufficiency. Mayo Clinic Proc. 2011;86(1): 50-60 Elsevier.

13. Kamen DL, Cooper GS, Bouali H, Shaftman SR, Hollis BW, Gilkeson GS. Vitamin D deficiency in systemic lupus erythematosus. Autoimmun Rev. 2006;5(2):114-7.

14. Hyppönen $E$, Läärä $E$, Reunanen $A$, Järvelin MR, Virtanen SM. Intake of vitamin D and risk of type 1 diabetes: a birth-cohort study. Lancet. 2001; 358(9292):1500-3.

15. Deluca HF, Cantorna MT. Vitamin D: its role and uses in immunology. FASEB J. 2001:15(14):2579-85.

16. Tamer G, Arik S, Tamer I, Coksert D. Relative vitamin D insufficiency in Hashimoto's thyroiditis. Thyroid. 2011;21(8):891-6.

17. Bozkurt N, Karbek B, Ucan B, Sahin M, Cakal E, Ozbek M, Delibasi T. The association between severity of vitamin D deficiency and Hashimoto's thyroiditis. Endocr Pract. 2013;19(3):479-84.

18. Aminorroaya A, Meamar R, Amini M, Feizi A, Tabatabae A, Imani EF. Incidence of thyroid dysfunction in an Iranian adult population: the predictor role of thyroid autoantibodies: results from a prospective population-based cohort study. Eur J Med Res. 2017;22(1):21.

19. Altrichter S, Boodstein N, Maurer M. Matrix metalloproteinase-9: a novel biomarker for monitoring disease activity in patients with chronic urticaria patients? Allergy. 2009;64(4):652-6.

20. Gaitonde DY, Rowley KD, Sweeney LB. Hypothyroidism: an update. S Afr Fam Pract. 2012;54(5):384-90.

21. Garber JR. Woeber for the American Association of Clinical Endocrinologists and American Thyroid Association Taskforce on hypothyroidism in adults KA. Clinical practice guidelines for hypothyroidism in adults: cosponsored by the American Association of Clinical Endocrinologists and the American Thyroid Association. Thyroid. 2012;22:1200-35.

22. Chambers ES, Hawrylowicz CM. The impact of vitamin D on regulatory $T$ cells. Curr Allergy Asthma Rep. 2011;11(1):29-36.

23. Evliyaoğlu O, Acar M, Özcabı B, Erginöz E, Bucak F, Ercan O, Kucur M. Vitamin $D$ deficiency and Hashimoto's thyroiditis in children and adolescents: A critical vitamin D level for this association? J Clin Res Pediatr Endocrinol. 2015;7(2):128.

24. Ucan B, Sahin M, Sayki Arslan M, Colak Bozkurt N, Kizilgul M, Güngünes A, Cakal E, Ozbek M. Vitamin D treatment in patients with Hashimoto's thyroiditis may decrease the development of hypothyroidism. Int I Vitam Nutr Res. 2017:1:9.

25. Krysiak R, Szkróbka W, Okopień B. The effect of vitamin D on thyroid autoimmunity in levothyroxine-treated women with Hashimoto's thyroiditis and normal vitamin D status. Exp Clin Endocrinol Diabetes. 2017;125(04):229-33.

26. Effraimidis G, Badenhoop K, Tijssen JG, Wiersinga WM. Vitamin D deficiency is not associated with early stages of thyroid autoimmunity. Eur J Endocrinol. 2012:167(1):43-819.

27. Colbay M, Altay M, Akturk M, Cakir N, Yetkin I, Arslan M. Vitamin D levels are associated with serum TSH levels but not with thyroid autoantibodies. In: 13th European Congress of Endocrinology, BioScientifica. 2011;26.

28. Zhang Q, Wang Z, Sun M, Cao M, Zhu Z, Fu Q, Gao Y, Mao J, Li Y, Shi Y, Yang F. Association of high vitamin d status with low circulating thyroidstimulating hormone independent of thyroid hormone levels in middleaged and elderly males. Int J Endocrinol. 2014;2014:631819.

29. Bársony J, Lakatos P, Földes J, Fehér T. Effect of vitamin D3 loading and thyroid hormone replacement therapy on the decreased serum 25 hydroxyvitamin D level in patients with hypothyroidism. Acta Endocrinol. 1986;113(3):329-34.

30. Cayir A, Turan Ml, Ozkan B. The effect of levothyroxine therapy on vitamin D and bone mineral density. In: In6th international conference on children, vol. 2; 2013. BioScientifica.

31. Fournier C, Gepner P, Sadouk MB, Charreire J. In vivo beneficial effects of cyclosporin a and 1, 25-dihydroxyvitamin D3 on the induction of experimental autoimmune thyroiditis. Clin Immunol Immunopathol. 1990;54(1):53-63.

\section{Publisher's Note}

Springer Nature remains neutral with regard to jurisdictional claims in published maps and institutional affiliations.

Ready to submit your research? Choose BMC and benefit from:

- fast, convenient online submission

- thorough peer review by experienced researchers in your field

- rapid publication on acceptance

- support for research data, including large and complex data types

- gold Open Access which fosters wider collaboration and increased citations

- maximum visibility for your research: over $100 \mathrm{M}$ website views per year

At BMC, research is always in progress.

Learn more biomedcentral.com/submissions 